\title{
Making the Absent Object Present: Towards a holographic museum of modern art (hMoMA)
}

\author{
Terence Quinn \\ Kingston School of Art and \\ University of the Arts London \\ 20 Matham Road, Surrey KT8 0SU, UK \\ terencemquinn@gmail.com
}

\begin{abstract}
Fifty-five thousand museums worldwide are custodians of our cultural legacy and over ninety-five percent of their collections are in storage and rarely, if ever, publicly displayed. This early practice based PhD research explores the viability and acceptability of improving public access to these hidden collections by using recently available digital technology. The aim is to enable museum visitors to walk around three-dimensional digital replicas of stored artefacts and moving subjects, as though these replicas are physically present in the real world exhibition space. Curatorial interpretation is envisaged from knowledge experts similarly replicated to appear alongside both digital and physical exhibits in the gallery. Whilst recognising that digital replicas are not the same as the real thing, if stored collections are rarely seen, this is the next best thing, and as technology improves will move even closer to a physical experience. The technology to create these three dimensional digital replicas is a portable volumetric capture rig, one of which has been assembled by the author. This consists of multiple miniature cameras, recording depth as well as image, mounted on portable stands, which are arranged in a circle around the subject. The cameras are connected to a computer and software, which synchronises the information provided by the cameras and creates and records static and moving point-cloud images rendered into life-like three-dimensional replicas either in real-time or in post processing. A person can view these threedimensional digital replicas using Mixed Reality (MR) smart glasses or headsets. These devices allow the user to walk around three-dimensional digital replicas as though physically present in the real-world environment, hence in MR. This is distinct from Augmented Reality (AR) which overlays two-dimensional images on the real world, and Virtual Reality (VR), which displays images in an occluded virtual world. Benefits include: Giving wider public access to collections without commensurate pressures to increase museum exhibition space; 3D replicas of repatriated exhibits can be displayed in donating institutions; The advantages of 3D scanning are no longer limited to static collections as moving contemporary art such as performance can be included (hence the title of this paper, Towards hMoMA). In this paper the author gives an overview of technology developments contributing to this research as well describing his own art practice, which combines digital replicas in mixed reality, binaural audio and physical art installations.
\end{abstract}

Museum. Archive. Digitisation. Culture. Heritage. Virtual. Volumetric.

\section{INTRODUCTION}

The Culture is Digital report published last year by the UK department of Digital, Culture, Media and Sport (DCMS) called for a more strategic approach to digitising collections led by the National Archives (GOV.UK 2019).

Museums currently digitise their collections in order to provide archival documentation and to allow the general public and researchers access to on-line images and interpretation through their in-house websites. However, practices and systems differ widely, hence the recommendation for a more strategic approach.

Recent conferences organised by the Museums Association have also focused on the issue of stored collections. This is particularly pertinent, given the opportunity afforded by planned moves of current stored collections including those of the V\&A (Sanderson 2019), Science Museum and British Museum from Blythe House in West London, and the creation of a new Museum of London in Smithfield (BBC News 2019). 
During the MA conference Making the most of stored collections (Museums Association 2019) which the author attended, Heather Caven, Director V\&A Collections Care, and responsible for the move from Blythe House, stated that due to lack of funding: "Very few museums have enough storage for the next ten years", and "Only $40 \%$ of museums have a storage plan".

These issues and opportunities led to the current direction of the author's research into the viability and acceptability of improving access to stored museum and gallery collections, by deploying the latest volumetric capture and mixed reality technologies. These technologies allow volumetric digital replicas of stored artefacts and moving subjects to be created and overlaid into a real-life environment using special glasses. As the replicas are digital copies of subjects and people displayed into a physical exhibition, there is no need for computer generated graphic images of artefacts, spaces or avatars, thus simplifying the process and skills needed. Each museum would create their own volumetric archive on their premises to complement their own archival documentation, exhibitions and chosen methods of distribution. It is envisaged that these volumetric archives would be held in the Cloud and accessed by museums using high-speed access available with fifth generation (5G) communication networks (Linthicum 2019).

Visitors to a museum or gallery would use these glasses (mixed reality headsets) to walk around digital replicas as though they are physically present in existing museum and gallery spaces. Curatorial interpretation could be included from knowledge experts captured and displayed as though in real life alongside digital and physical exhibits. Temporary art installations, performance and digitally dependent art can be included as the process is not limited to static artefacts such as painting, sculpture and articles of historic interest.

Benefits of these proposals include:

- Stored collections digitally displayed and experienced in a similar way to their physical counterparts in the same gallery space, making more collections accessible without commensurately expanding existing museum exhibition space

- Temporary exhibitions can be reexperienced

- Fragile artefacts can be exhibited where before they could not be publicly displayed

- Exhibitions can be curated using works already in a museum's physical collection together with digital replicas from partner organisations without the necessity for loans and transportation
- Exhibitions can be extended to remote locations without moving them physically

- Artefacts can be repatriated leaving digital replicas in the donating museums

- Digitally dependent art can be volumetrically captured and re-experienced in mixed reality, potentially avoiding the need for more involved long-term conservation of the original due to rapid technological change.

It is important to understand the response to these ideas by museums, art institutions and all their stakeholders including artists and audiences. A practical demonstration of what is possible with current technology is the purpose of the practicebased element of this research, as is observation of its implementation in a museum setting.

\section{MA RESEARCH}

The author's MA research paper Digital to Physical - Made to Last? Will functioning digital art be part of our future cultural heritage? (Quinn 2016) explored the issues surrounding built-in obsolescence of digitally dependent art due to rapidly changing technology, and implications for its long-term conservation. It concluded that there will be a future 'digital-gap' in collections of art representing the best of that produced during this digital age.

Two of the author's MA practice based projects also inform this $\mathrm{PhD}$ proposal. Firstly, the author's art installation The Refugees' Crisis (Quinn 2017b). This comprised a traditional art installation, including sculpture and video with additional layers. Visitors, using headphones with built-in audio recorders, could walk around and listen to, actors performing an associated binaural recorded narration. Then, wearing a Microsoft HoloLens headset, they could also view the physical installation alongside vast digital replicas of the sculptures placed around the gallery. This exhibit at UAL Camberwell College of Art MA Show in 2017, became the subject of a BBC Radio 4 documentary for iPM later that year, and was re-presented at St Hugh's College Oxford University for The Oxford Italian Association in 2018.

Secondly, Making the absent object present (Quinn 2017a). Using a hand held scanner (a Mini iPad with Occipital Structure Sensor and ItSeez3D cloud based services) the head of an artist's model was 3D scanned, 3D printed and downloaded as a digital replica into the Microsoft HoloLens Development Edition. This was demonstrated (jointly with Susan Aitchison, an MA student in Museum and Gallery Studies at Kingston University) to Kingston University visitors who first 
viewed the physical object on a plinth, then when removed, the digital replica on the same plinth. This demonstration was repeated at the V\&A South Kensington to staff from the V\&A education department.

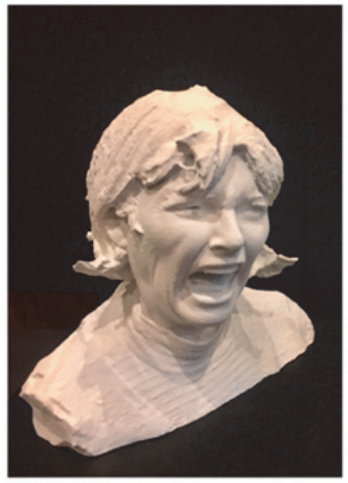

Physical sculpture

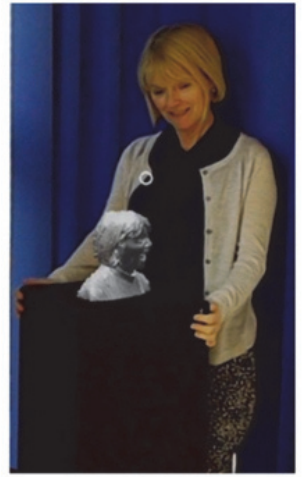

Virtual replica seen with Microsoft

HoloLens
Figure 1: T. Quinn, 2017.

\section{MUSEUMS ARE UNDER PRESSURE TO MAKE MORE OF THEIR COLLECTIONS PUBLICLY ACCESSIBLE}

To illustrate the issues raised in this research, a 'cannibal' trough looted by Captain Edward Davis from the Solomon Islands in 1891 was displayed for the first time last year at the Royal Academy of Arts Oceania exhibition after it had been kept in storage for over a century at the British Museum. Around $99 \%$ of the British Museum collections are in storage including the now returned to storage 'cannibal' trough (The Art Newspaper 2019).

The Fine Art Warehouse (Groskopf 2016) also carried out detailed research in forty-eight of the world's most famous art museums to discover how much fine art is in storage and not on display, and found that:

\section{"Much of the world's great art is housed in the vast archives of museums with limited display space. The largest museums typically display about $5 \%$ of their collection at any time."}

To display a museum artefact requires more space than keeping it in storage, and in more accessible and expensive buildings. Thus, only a fraction of what is collected can be physically exhibited.

From the perspective of our cultural legacy, many artworks representative of the best from our digital age will be missing from public collections. Much digitally dependent art is not collected, due to builtin obsolescence arising from rapid technological change, and consequent conservation issues and associated costs. It is instead often shown in blockbuster temporary exhibitions, with the artworks returned to the owner or artist after the show ends, leaving conservation responsibility with them, which is most often unforthcoming.

In the meantime, most museums and art institutions continue making acquisitions. As these are acquired largely at taxpayer's expense, for the benefit of the general public and future generations, it begs the question "how is it all going to be seen, and where is it all going to go?"

\section{DIGITAL REPLICAS}

Viewing digital replicas is not the same as seeing the original, but if stored collections are rarely seen, digital replicas are proposed as a good alternative, and as technology improves they will move even closer to a physical experience. Substantial investments are currently being made in AR and MR by commercial companies such as Google, Intel, Sony, Microsoft, Apple and others to make this vision a reality. While these public company investments are rarely published, those attracting venture capital in 2018 alone obtained in excess of a billion dollars (AREA 2019).

This research focuses on creating digital replicas to be experienced in a way that is as close as possible to the real world, allowing visitors to view life size digital replicas alongside physical exhibits, curated by virtual knowledge experts. This means using volumetric capture of real subjects overlaid on the real world using mixed reality. This contrasts with virtual reality, which would only allow the viewer to see digital replicas in a virtual environment cut off from the real world exhibition space. It also means the avoidance of computer generated imagery (CGI) and avatars.

MR visors and smart glasses allow the wearer to see the real world, and walk around digital replicas with six degrees of freedom (6DoF) as though these replicas are physically present in the exhibition space. In this way digital replicas of collections can co-exist with physical collections, and digital replicas of real life knowledge experts can curate the combined exhibition.

A specific example of the benefit of digital replicas is the potential saving in storage as well as exhibition space for the work of Nam June Paik exhibited by ZKM Center for Art and Media, Karlsruhe, Germany. Paik's artworks are frequently made up of multiple working old television sets. The ZKM store vast quantities of these sets as backup in an aircraft-hanger size warehouse, in case those in the exhibited works no longer function and cannot be repaired (Weibal in Serexhe 
2013, p.192). Perhaps such extensive steps to conserve Nam June Paik's work could be substantially reduced if a digital replica of the entire art installation served as backup instead?

\section{RECENT MUSEUM EXPERIENCE WITH VIRTUAL REALITY}

There are innovative smartphone and tablet apps, including one by Intel which opened an AR portal to Smithsonian's Burning Man Exhibit using Snapchat Lens (Palladino 2018) and David Bowie Is, a reprise in AR of the David Bowie exhibition at the V\&A (DavidBowielsReal 2019). However, these virtual images are still experienced in 2D through the window of a smartphone or tablet.

The benefits of experiencing exhibits in 3D are demonstrated by mostly temporary exhibitions, including those recently seen by the author, such as The Ochre Atelier VR experience of Modigliani's studio at Tate Modern (Tate 2019), Hold the World, with a volumetrically recorded David Attenborough interacting with computer generated $3 \mathrm{D}$ images of specimens at the Natural History Museum (Factory42 2018), Tim Peake in Space Descent $V R$, seen re-entering Earth's atmosphere in virtual reality at the Science Museum (Science Museum 2019), and the Magritte VR exhibition in Knokke Heist, Belgium (Art 2017).

However, these are all experienced in a virtual occluded environment isolated from the real world, albeit with a field of view (FOV) close to that achieved with the human eye.

Closer to a real world experience is an example using a mixed reality app developed for the Microsoft HoloLens. This allows 3D images to be seen in real-life scale that can be projected into the home using Microsoft HoloLens mixed reality glasses. It was developed by Case Western Reserve University, USA and Boulevard Arts, USA, and enables virtual visits to impressionist paintings from London's Courtauld Gallery and ancient Egyptian artefacts from the British Museum (BLVRD 2019).

Scanning, and making a 3D representation of a static object, has been possible for some time. The Boulevard Arts app for example involved digitally capturing paintings and artefacts in 3D using an Artec Eva full colour precision scanner and its associated photogrammetry software Artec Studio 13. However, these are static objects experienced in mixed reality with a restricted FOV of around 30 degrees using HoloLens Development Edition. In real life subjects can move and a human's FOV is around 180-190 degrees. While FOV has been improved to around 40 degrees with a Magic Leap headset or 50 degrees with the recently announced HoloLens 2 (UploadVR 2019) it is well behind 110 degrees achieved with VR headsets and far short of the 180 to 195 degrees a person experiences in real life.

Recent technical advances now include 3D scanning of moving subjects. Factory42 (based in Somerset House London) made the Hold the World app, which involved volumetrically recording David Attenborough, at Microsoft's Seattle headquarters, inside a green screen studio incorporating 106 depth and photographic cameras.

Software was used to substitute the green screen background, so that the volumetrically captured images of the presenter could be placed into a CGI created 3D image of the Natural History Museum library and similarly $\mathrm{CGI}$ created 3D images of specimens in the museum's collection (Factory42 2018). There is now a similar Microsoft partner studio in Wimbledon, UK called Dimension (Storey 2019).

Making 3D scans of moving subjects without a green screen is another forward step. Intel is currently constructing an aircraft-hanger size, domed, volumetric film studio close to Los Angeles airport (Intel Newsroom 2018a). There is no green screen or any specially positioned cameras. Artificial Intelligence and other computer applications are used to edit the volumetric films after a shoot in post-production (Intel Newsroom 2018b).

American football pitches are being equipped with the same volumetric capture facilities using Intel True View, so that the entire action on the pitch is captured in 3D and can be relayed to viewers in their homes. It is envisaged that the viewer, using a VR headset linked to the Cloud (and in future over fifth generation $5 G$ networks), can virtually place themselves beside the pitcher if they wish, and view the game from the pitcher's perspective as though they were actually there. This is also being implemented in the UK Etihad, Anfield and Emirates stadiums so that from March 2019 fans of Arsenal, Liverpool and Manchester City football teams can enjoy Premier League matches in the same way (E\&T 2019).

At the same time as volumetric capture is advancing, so is the form factor of the special glasses that need to be worn to view these images. It is known that Apple are working on this. At the Mobile World Congress event in Barcelona during March this year (when the HoloLens 2 was announced), NReal demonstrated a similar pair of glasses and are partnering with Qualcomm using the latest Snapdragon $8555 \mathrm{G}$ mobile platform (more advanced than that used in HoloLens 2). 
These glasses are connected by a USB-C cable to a smartphone equipped with the Snapdragon chip which together provides a 52-degree FOV mixed reality experience in high-definition 1080p resolution (Reality Technologies 2019).

Technology is advancing towards a situation where digital replicas can be projected into the real world by wearing glasses similar to normal spectacles. Additionally, towards the possibility to volumetrically capture all types of museum artefacts and exhibitions, including those in contemporary art museums where subjects are not just static objects but include, for example, performance and art installations.

\section{PRACTICE BASED PHD PROJECT}

The author recognises that there are still many technical and other challenges to be resolved before the concept of hMoMA can become an established proposition in a museum setting. It is hoped that this practice based research will identify, and perhaps overcome, some of the most important obstacles and that technical advances during the remaining several years of this research will improve the experience to the point that it can become a practical reality, or at least where it can be deployed in limited circumstances.

This practice-based research has recently involved setting up a portable multi camera Volumetric Filmmaking (VF) rig (Intel 2018). The cameras are mounted on portable stands in an inward facing circle up to six metres in diameter (which can be expanded up to ten metres). Eight RealSense model D415 depth/RGB cameras on portable stands are connected by Newnex specialist repeater cables to eight USB Type C ports on a top specification Intel Hades Canyon NUC Windows 10 Mini PC (Intel 2018). This has an adapted Intel internal graphics card equivalent to an NVIDIA i6, but a more powerful external graphics card can be attached if necessary (a GTX 980 is available). Associated Intel software synchronises and integrates the input from all attached cameras into a $3 \mathrm{D}$ rendered static or moving point cloud image. This configuration includes 2 terabytes (TB) internal and 2TB external solid state discs (SSD) to store approximately 30 to 40 minutes of volumetrically captured moving image.

As it is impractical to transport museum collections to an external studio such as those previously described, it is important that the rig is portable. The rig can then be easily set up and calibrated in a museum storage area or display space. A static object can be placed inside the circle and one snapshot can capture the entire object from all angles simultaneously. A similar process is used for moving subjects. A green screen is not required as the system allows it to focus scanning on a predetermined area.

It is also proposed to make a moving digital replica of a curator. An example is from Dublin (Volograms 2019). The research aim is to provide an example of human voiced exhibit interpretation. Sound recordings will be made using binaural (spatial) audio recording devices (Binaural Enthusiast 2019a). Examples of binaural recordings must be listened to using normal headphones (Binaural Enthusiast 2019b).

Real life curators can then be viewed digitally in mixed reality alongside digital replicas of exhibits and physical collections. Museum visitors will be able to view digital replicas alongside physical collections and see and listen to a curator as though the narrator is speaking to them personally. Similar facilities for small-scale volumetric filmmaking have been recently announced by USA based immersive studios Evercoast (2019) and Jaunt (2018). These studios primarily target visual entertainment and computer game industries.

An objective under consideration for this research is to use the volumetric capture rig to speed up $3 D$ scanning and cataloguing of museum collections. This would contribute towards demonstrating the cost/benefit case to museums to use the rig for 3D scanning their stored collections. The Science Museum is currently using handheld scanners at Blythe House to 3D scan tabletop sized artefacts. Museum staff 3D scan an object by walking around the exhibit while pointing the scanner at it and taking care that all its surfaces are completely recorded. These digital images are then reconstructed into a 3D image using photogrammetry software provided with the scanning device. This software is linked to a cataloguing software system using Asset Panda technology. Barcodes are placed alongside objects to be scanned so that the resultant $3 \mathrm{D}$ scans are directly input to the museums archival documentation system. The scanning process takes on average five to six minutes per scanned item plus ten minutes to link an image to data. This linkage has saved ninety-one thousand hours to manage the process for 300,000 stored objects (Fullerton 2019).

Using a static rig instead of a handheld scanner could potentially further reduce the long timescales required for museums to $3 \mathrm{D}$ scan and catalogue their entire collections.

It is envisaged that these virtual digital replicas will be uploaded to Cloud based systems by museum staff and downloaded by museum visitors while wearing mixed reality glasses in the exhibition 
space. To be effective in volume this will require the use of $5 \mathrm{G}$ networks and will need to be tested at a later stage when these networks, and devices using them, are commercially available (CBS News 2019).

This practice based research pilot will operate as follows: Digital replicas made using the VC rig will be prepared for the Microsoft HoloLens 2. The extent of this preparation will depend upon the application software available for the HoloLens at that time. Currently, it involves transfer of the digital images to a file format and 3D mesh size accepted by the device, and possibly embedding the $3 \mathrm{D}$ objects into a scene using Unity and Microsoft Visual Studio. It is hoped that this process will be simplified in future releases of HoloLens software infrastructure. The result is then uploaded from the Intel NUC mini-computer to Microsoft OneDrive, a cloud based storage system from where they are uploaded to the HoloLens 2. The mixed reality experience using the HoloLens can then be tested in an exhibition space.

The author has experienced Magic Leap (the main competitor to HoloLens) but prefers the infrastructure of the Microsoft HoloLens, is familiar with it and believes that the HoloLens 2 will give a superior result. Future developments in display technology referred to earlier will be tested when available.

When successful in a studio, it is the intention that the pilot is tested in a museum, first with museum staff, then with museum visitors. In order to refine the experience, it will be necessary to make observations of the viability of the process in a museum setting, as well as acceptance of the concept by museum staff, and of artist and audience response.

The author has had preliminary discussions with a museum and a digital studio around the possibility of his practice based research contributing towards their internal projects. Holition, a digital studio based in Holborn, London is currently working with UAL London College of Fashion and the V\&A to immersively capture some of the V\&A's fragile stored fashion collection for public display. This is partly funded by Innovate UK. Additionally, The Museum of London is seeking partnerships to develop a similar funding application for digitally displaying current exhibits and stored collections in innovative ways ready for the Museum's move to Smithfield, London.

\section{DEMONSTRATION}

If time allows, the presentation will include a demonstration of digital replicas seen using both a HoloLens2 visor, and a Looking Glass holographic volumetric display (which does not require a headset). The RealSense volumetric capture devices will also be on show.

\section{REFERENCES}

AREA (2019) https://thearea.org/ar-news/the-10biggest-ar-investments-of-2018/ (retrieved 19 March 2019).

Art, S. (2019) Magritte VR, Surrealism Today. https://surrealismtoday.com/magritte-vr/ (retrieved 19 March 2019).

BBC News (2019) Museum of London move gets $£ 180 \mathrm{~m}$ funding boost.

https://www.bbc.co.uk/news/uk-england-london$\underline{38732919}$ (retrieved 19 March 2019).

Binaural Enthusiast (2019a)

https://binauralenthusiast.com/ (retrieved 19 March 2019).

Binaural Enthusiast (2019b)

https://binauralenthusiast.com/examples/ (retrieved 19 March 2019).

BLVRD (2019) http://blvrd.com/ (retrieved 19 March 2019).

CBS News (2019) What a $5 G$ world could look like: 3D holograms, faster $\mathrm{Al}$ - and new security concerns. https://www.cbsnews.com/news/what-a5g-world-could-look-like-3d-holograms-ai-newsecurity-concerns/ (retrieved 19 March 2019).

DavidBowielsReal (2019) David Bowie Is https://davidbowieisreal.com/ (retrieved 19 March 2019).

E\&T (2019) Intel 'True View' puts football fans at the heart of the action.

https://eandt.theiet.org/content/articles/2019/02/inte I-true-view-puts-football-fans-at-the-heart-of-theaction/ (retrieved 19 March 2019).

Evercoast (2019) Evercoast Volumetric Capture. https://www.evercoast.com/ (retrieved 19 March 2019).

Factory42 (2018)

https://www.factory42.uk/holdtheworld (retrieved 19 March 2019).

Fullerton, A. (2019) Presentation of Science Museum decant from Blythe House. Making the most of stored collections, British Museum, 3 December 2018. 
GOV.UK (2019)

https://assets.publishing.service.gov.uk/governmen t/uploads/syatem/uploads/attachment data/file/687 519/TT v4.pdf (retrieved 19 March 2019).

Groskopf, C. (2016) Museums are keeping a ton of the world's most famous art locked away in storage. https://qz.com/583354/why-is-so-much-ofthe-worlds-great-art-in-storage/ (retrieved 19 March 2019).

Intel (2018) Intel RealSense Depth \& Tracking Cameras. https://realsense.intel.com/intelrealsense-volumetric-capture/ (retrieved 19 March 2019).

Intel Newsroom (2018a) Intel Studios: A Home for Volumetric Video Capture and Creation. https://www.youtube.com/watch?v=nd6vrSL7i1s (retrieved 19 March 2019).

Intel Newsroom (2018b) Intel Studios Debut Volumetric Video Demo https://www.youtube.com/watch?v=9qd276AJg-o (retrieved 19 March 2019).

Jaunt (2018) Jaunt Augmented Reality Research and Development.

https://www.youtube.com/watch?v=LUE5IKxq2ow (retrieved 19 March 2019).

Linthicum, D. (2019) 5G will bring cloud computing to everyone.

https://www.infoworld.com/article/3308378/5g-willbring-cloud-computing-to-everyone.html (retrieved 19 March 2019).

Museums Association (2019) Open Up: Making More of Stored Collections.

https://www.museumsassociation.org/events/openup (retrieved 19 March 2019).

Pallatino, T. (2019) https://mobile-

ar.reality.news/news/intel-opens-ar-portalsmithsonians-burning-man-exhibit-via-snapchat0186750/ (retrieved 19 March 2019).

Quinn, T. (2016) Research Paper: Digital to Physical - Made to Last? Will functioning digital art be part of our future cultural heritage? https://terencemquinn.com/2016/10/05/research- paper-digital-to-physical-made-to-last-will-

functioning-digital-art-be-part-of-our-future-culturalheritage/ (retrieved 19 March 2019).

Quinn, T. (2017a) Portfolio - October 2017.

https://terencemquinn.com/2017/10/ (retrieved 19 March 2019).

Quinn, T. (2017b) The Refugees' Crisis.

https://terencemquinn.com/2017/06/19/bookmarkfor-the-refugees-crisis/ (retrieved 19 March 2019).

Reality Technologies (2019) nreal and Qualcomm Partner Up for 5G. https://www.realitytechnologies.com/nreal-andqualcomm-partner-up-for-5g/ (retrieved 19 March 2019).

Sanderson, D. (2019) V\&A is turned inside out to win space race, The Times.

https://www.thetimes.co.uk/article/d38063e8-de2311e8-8469-be4fc9fcee5f (retrieved 19 March 2019).

Serexhe, B. (ed.) (2013) Digital art conservation. Preservation of digital art: Theory and practice. Germany: Ambra V and ZKM Center for Art and Media.

Storey, D. (2019) An evolutionary step in imaging. https://www.dimensionstudio.co/ (retrieved 19 March 2019).

The Art Newspaper (2018) Looted 'cannibal' bowl served up in Royal Academy of Art's Oceania show.

https://www.theartnewspaper.com/preview/lootedcannibal-bowl-served-up-in-royal-academy-soceania-show (retrieved 19 March 2019).

Tate (2019) Modigliani VR: The Ochre Atelier. https://www.tate.org.uk/whats-on/tatemodern/exhibition/modigliani/modigliani-vr-ochreatelier (retrieved 19 March 2019).

UploadVR (2019) HoloLens 2's Field of View Revealed. https://uploadvr.com/hololens-2-field-ofview/ (retrieved 19 March 2019).

Volograms (2019) Volumetric Video.

http://volograms.com/ (retrieved 19 March 2019). 